\title{
LLAMADOS POR EL PROPIO NOMBRE
}

\author{
De la "Pastoral Vocacional" \\ a la praxis del llamamiento
}

DOI: https://doi.org/10.52039/seminarios.v51i175.732

Autor: Luis Rubio Morán. Sacerdote Operario Diocesano. Director espiritual del Seminario de la Arquidiócesis de Évora (Portugal).

Llamar-llamamiento es categoría antropológica fundamental para comprender al ser humano. Llamamiento como expresión de amor, acompañado de la mirada. Dios llama y constituye la asamblea de llamados (Ecclesia), llama por el nombre y lo cambia para indicar la misión. 
ción existencial o condición de vida (vocación cristiana, matrimonial, sacerdotal, religiosa) ${ }^{1}$. En todos estos casos ha perdido casi por completo la connotación original de una actividad de la voz (voc-are), 1lamar, y del sustantivo activo correspondiente, el llamamiento.

Señal de esta pérdida y olvido la tenemos en los mismos Diccionarios de Teología Bíblica, en los que el término "llamar", tan frecuente en la Biblia, o se omite, o, cuando se incorpora, no se explica, remitiéndose a los sustantivos "elección" o"vocación"2.

La misma laguna se observa en el lenguaje pastoral. El término "reclutamiento", que durante mucho tiempo designó toda la acción en favor de las vocaciones eclesiásticas, ha sido abandonado y sustituido por otros varios, como promoción, animación, acompañamiento, discernimiento, o, como en el último Congreso Europeo de vocaciones, por "sembrar, acompañar, educar, formar, discernir", sin que se incluya entre ellos explícitamente el llamar o el llamamiento.

Una tímida reacción frente a este olvido la encontramos en el interés, manifestado muy recientemente, sobre la fórmula "1lamar por el propio nombre", que ha dado lugar ya a una, relativamente abundante, bibliografía 3 . Y, sobre todo, en la valoración de que está siendo objeto la categoría del "llamar" por parte de la reflexión filosófica contemporánea, con una todavía tímida pero ya significativa repercusión en los planteamientos pastorales.

1 Véase a este respecto nuestro estudio Orientaciones doctrinales para una pastoral eclesial de las vocaciones, Seminarium 31/4(1991)697-725.

2 Así ocurre en los tan conocidos y estimados Vocabulario de Teología Bíblica, de Leon-Dufour, en el Vocabulario práctico de la Biblia, de Grabner-Heider, en el Diccionario de Teología Bíblica, de Bauer, en el Diccionario de la Biblia, de Haag-Van der BornAusejo. El Vocabulario Bíblico, de Von Allmenn, en cambio, no contiene el término vocación, sino el verbo "llamar". Asimismo el Diccionario Teológico del Nuevo Testamento, de Coenen-Beyreuther-Bietenhard, en la voz "vocación" se remite a la voz "llamada", que expone los términos de raíz kal(eo)-kle(sis) del griego.

${ }^{3}$ Con el título explícito de Llamados por su nombre, centrados en la frase bíblica y referido a diversas narraciones vocacionales bíblicas han aparecido los de J. Pikaza (Claretianas, Madrid 1998), P. van Breemenn (Sal Terrae, Santander 2000), A. Sicari (Paulinas, Madrid 1981). El de P. Sanna, aunque con el mismo título (Chiamati per nome, San Paolo, Torino 1994) es una "antropología teológica" clásica, pero que no entra en el análisis de la fórmula bíblica. Con el mismo título existen frecuentes, aunque muy breves y muchas veces tópicas, comunicaciones en varias Revistas vocacionales, como Rogate (ver n. 2,1995); Vocazioni (n.1, 1993); Se Vuoi (n.1, 1995); Seminary News (n.3, 1992). 
Vamos a tratar, pues, del llamar; del llamamiento (en algunos países americanos se usa el término "llamado") en su sentido propio, activo y concreto: la acción de pronunciar oralmente, en voz alta, el nombre de alguien, de invitarle a venir, a ver, a empeñarse en una tarea o actividad, a emprender un camino, a orientarse en una determinada dirección existencial.

Expondremos, en un primer momento, el sentido y la riqueza del llamar-llamamiento en una perspectiva simplemente antropológica. Estudiaremos después el alcance teológico-espiritual a partir de la formulación bíblica "llamar por el propio nombre". Y, finalmente, veremos cómo dicha acción puede llevarnos a pasar de la "pastoral vocacional" a la praxis del llamamiento.

\section{PERSPECTIVAS ANTROPOLÓGICAS}

El "llamar-llamamiento" es considerado por la reflexión filosófica, desde hace ya algunas décadas, como una de las categorías fundamentales en la comprensión del ser humano. En ello ha influido tanto la "filosofía del lenguaje" como, y sobre todo, las corrientes calificadas como "filosofías de la alteridad", marcadas estas últimas por una positiva influencia del pensamiento bíblico y cristiano (Bergson, Marcel, Levinas, Ricoeur, y, entre nosotros, Zubiri, Laín Entralgo, Julián Marías).

\section{El Llamar-llamamiento como fuente del ser personal: soy lla- mado, luego existo.}

\section{Entre el "auto-nombramiento" y el "anonimato".}

La cultura actual acentúa una doble tendencia calificada con razón como "antivocacional", la del "autonombramiento" o exaltación de sí mismo, y la del "anonimato", o el hombre sin nombre, sin rostro, el hombre-masa, reducido a un número.

El "autonombramiento" trae su origen y conoce sus primeras manifestaciones en el ideal de hombre formulado ya por la filosofía 
griega, como se manifiesta en el conocido principio: "conócete a ti mismo", que entraña el descubrir sus potencialidades, consideradas como riquezas propias, desarrollarlas al máximo y por sí mismo, sin cualquier influencia exterior que pudiera condicionarlo, orientarlas en su propio y exclusivo provecho, y encontrar el máximo de felicidad en la contemplación ensimismada de su propia belleza (Narciso).

Se formula de nuevo y se acentúa en la modernidad a partir del famoso principio cartesiano "pienso, luego existo". Por el pensamiento, por la razón, el hombre capta, comprende la realidad, domina el mundo, se constituye dueño del universo. Este dominio, que proporciona al hombre la conciencia de su poder, le hace grandioso a sus propios ojos, le permite afirmarse a sí mismo, le procura una íntima y profunda satisfacción, le ofrece la confirmación de su existir. En ello se complace y por ello se siente "realizado". El "yo" del hombre moderno se construye y afirma como existente, se considera a sí mismo "siendo" siempre, cuando y en la medida en que, por el conocimiento científico, sabe-conoce el funcionamiento del mundo cósmico y humano, y, por la técnica, lo maneja, lo usa para su propio provecho y disfrute, lo pone al servicio de la satisfacción de sus necesidades y deseos, proporcionándole un efectivo bienestar, una extensa sensación de felicidad.

Esta tendencia se exacerba en la concepción actual, post-moderna, según la cual el ser del hombre se hace consistir en la experiencia de emociones, de gustos, de sentimientos, de afectos. Su principio existencial parecería ser el de "siento, luego existo". Soy porque y en la medida en que siento. Lo que siento, lo que me gusta, lo que me relaja, lo que "me mola", como se dice en el argot juvenil, es lo que me hace existir. Volcado hacia este su mundo interior de gustos, sentimientos y afectos este hombre se instala en un solitario individualismo, preocupado solo de su mundo interior. Mira la realidad exterior, y, sobre todo, a los otros, en cuanto objetos de su propio e íntimo "sentirse bien", se relaciona con ellos como y en cuanto colman su insaciable sed de bienestar, de reconocimiento, de aplauso, de éxito, de caricia. Cualquier voz o eco externo será considerado como algo molesto, turbador de su propia felicidad, será por tanto apartado de su oído. Inmerso en su propia entraña, será incapaz de abrirse a cualquier voz extraña, a algo o a alguien que, llamándolo, desde fuera, pueda turbar su narcisista autocomplacencia. 
Siendo este mundo interior de los sentimientos, gustos y deseos tan confuso, cambiante e indefinido, nada sorprenderá que este sujeto se manifieste radicalmente indeciso, se instale en la vivencia del momento-instante presente, sin proyecto personal definido, sin coraje para afrontar el riesgo de lo desconocido, la aventura de la salida de sí que cualquier llamamiento suscita y provoca.

Este "yo", contemplado y pronunciado por él mismo, apoyado solo y exclusivamente en sí mismo, resulta un yo sin nombre, un yo "anónimo". Al juntarse con otros, también sin rostro personal, se cae en la "homologación", se convierte en multitud, en hombre-masa (Ortega y Gasset), en "manada" (Guardini), en "rebaño" (Cencini), buscador de: el "calor tibio del establo" (E. Fromm). "Es forzoso constatar que una franja cada vez mayor de jóvenes, más que elegir acaba siendo ella elegida por una infinidad de... agentes de decisión más o menos evidentes... por las diversas "agencias de colocación" (los padres, el mercado, el agrado social...), para quienes el máximo de subjetivismo expresivo se vierte en el máximo de homologación objetivadora: se elige lo que convencionalmente es elegido, sin saber ni querer saber por qué... El grupo, todos los que lo componen, son iguales al yo de cada uno, y cada uno se elige porque es espejo (narcisista) del otro... (El grupo tiende a) "convertirse en rebaño" en el que se buscan unos a otros sobre todo para encontrarse a sí mismos"4.

\section{Soy llamado, luego existo}

Frente a estas perspectivas se afianza cada vez con mayor hondura, calidad y firmeza, el principio antropológico formulado en estos términos: "soy llamado, luego existo", con el que se expresa la convicción de que el llamar-llamamiento constituye fuente y raíz del existir auténticamente humano.

La filosofía del lenguaje descubre y proclama la importancia del hablar, que caracteriza esencialmente y especifica al ser humano. No hay "ideas innatas, claras y distintas", en las que el hombre pueda

${ }^{4}$ A. Cencini, Alguien te llama. Carta a un joven que no sabe que es llamado, Sal Terrae, Santander 2000, 40-42.44). 
encajar la realidad. La "tabula rasa" que es el hombre al nacer se va imprimiendo con los nombres y palabras que nos son sugeridos desde fuera por el entorno en que se desarrolla la vida de cada persona. Con esas palabras aprendidas desde los primeros balbuceos, comenzamos a "dar nombre" a la realidad (cfr. Gn 2,19-20), y así, la realidad nombrada comienza realmente a existir para nosotros. Lo no nombrado, aquello que no sabemos cómo se llama, propiamente no existe para nosotros, no lo hacemos nuestro5. Mediante la palabra sugerida y aprendida, el caos del mundo se hace cosmos, y cosmos humano, ordenado, organizado6.

Lo mismo acontece con el mundo interior del hombre, el mundo del sentir. En sí mismo se experimenta como un magma confuso, indis-

${ }^{5}$ Bien lo han intuido y mejor lo formularon algunos de nuestros modernos poetas más insignes. Así Pedro Salinas cantará: /Por qué tienes nombre tú /día, miércoles? /Por qué tienes nombre tú /tiempo, otoño? /Alegría, pena, siempre, /¿por qué tenéis nombre: amor? /Si tú no tuvieras nombre, /yo no sabría qué era /ni cómo, ni cuándo. Nada..." (La voz a tí debida). Así también José HIERRO: /No tengo miedo nombraros /ya con vuestros nombres, /cosas vivas, transitorias... /Mías sois, cosas fugaces, /bajo marchitables nombres... /Pero sois yo, soy vosotras... /Nombraros ¿no es poseeros /para siempre, cosas, nombres?/ (Poema, Nombrar perecedero, del libro Cuanto sé de mî́).

${ }^{6}$ En la conocida Tercera página del periódico $\mathrm{ABC}$, en un artículo titulado Nos quedan las palabras, Ferrán Gallego, profesor de Historia en la Universidad Autónoma de Barcelona, hablando de la perversión del lenguaje realizada en los campos de concentración y sus efectos sobre las personas, sintetizando la narración de J. Améry en Más allá de la culpa y la expiación, dice: "Ni la violencia física ni el hambre ni el frío ni el encuentro con la condición meramente corporal del individuo reducido a un ente biológico elemental fueron tan arteros y penetrantes como el uso indebido del lenguaje, su extraviada manipulación por los verdugos y los presos comunes para conseguir crear una sociedad de esclavos en el recinto penitenciario. Porque esa perversión del lenguaje invertía el mundo, lo hacía irreconocible y adverso. Y, además, hacía de quienes lo habían poseído a través de la cuidadosa arquitectura del idioma, unas víctimas recluidas en el silencio, incapaces de controlar la existencia conservando el valor de las palabras, las mismas que les habían permitido el conocimiento, el poder sobre las cosas, el reinado del hombre y la soberanía del espíritu".

Y hablando del mismo fenómeno, presente en y fruto de la cultura actual, continúa: "La destrucción del lenguaje no ha sido la pérdida de este o aquel idioma, sino la traición a la palabra en su sentido universal, a lo que, traducido a cualquier lengua, las cosas significan, nos dan a conocer, nos permiten hacernos con el mundo, comprenderlo y explicarlo... Quizás el pasado siglo ha sido en buena medida un penoso malentendido verbal y haya que empezar de nuevo. No desde la nada, sino desde una vieja tradición liberal, ilustrada, abierta humanista. Tal vez para dirigirnos a las generaciones que nos siguen y decirles, en los términos en que también lo señaló Espríu: "Hemos vivido para preservaros las palabras, para señalaros el recto camino de acceso al pleno dominio de la tierra" (ABC, 30-VII-2004). 
tinto, múltiple. Gracias a las palabras aprendidas, clasificamos, distinguimos, organizamos ese mundo confuso, y así, al nombrarlo, poseemos y dominamos el mundo de nuestros sentimientos. La palabra, pues, el nombre, aprendido, de nuestros pensares y de nuestros sentires, nos dan la posesión de nosotros mismos, la conciencia de que existimos, el saber que somos.

Por otra parte, por la palabra y los nombres esa autoposesión de nosotros y del mundo se proyecta hacia los otros. Si no se hace palabra para otros nos instalamos en el monólogo interior, en una especie de "autismo" aislante y destructor. La palabra es el medio primordial que nos pone en relación con los otros, que hace posible y efectivo el encuentro con ellos, y así el construirnos como humanos. Con la palabra y por ella yo me expreso y revelo al otro, salgo de mí, y, a su vez, el otro, por su palabra, puede entrar en mí. El encuentro se realiza, pues, en esa especie de éxodo, de ex-sistencia. Mi palabra es por sí misma llamada para él, y si la acoge, puedo entrar en él, y, de alguna manera, habitar en él. Hacerme "una sola carne" con él. Con ella y por ella informo y me informo, adquiero forma y con-formo al otro. Por la palabra, pues, yo y el otro, nos sentimos llamados, interpelados, provocados, nos convertimos mutuamente en un "tu".

Esta perspectiva ha sido profundizada y enriquecida por la conocida como filosofía de la alteridad, cuyo principio básico afirma que el otro, el tú, es el factor esencial para la conformación del yo humano, de la propia identidad, de la conciencia y realización de sí.

La experiencia primordial de todo ser humano es la de ser llamado. "Todos nos hemos sentido llamar "tú" antes de poder decir "yo". La experiencia primordial del acceso al YO es la de la segunda persona. La identidad se construye por y en el conjunto de comunicaciones sociales en las que le es dado al sujeto entrar. Hablando la lengua aprendida es como cada individuo se constituye como persona"7. Aprendemos a decir "yo" en el contacto con la voz de un tú que pronuncia nuestro nombre. Dejada la persona a sí misma, en soledad absoluta, el hombre no llega a saber quién es. El nombre que tenemos es el que otros nos dan, el que otros pronuncian, por el que nos llaman y

7 Villepelet,D., Appeler à plus!, Jeunes et Vocations, n. 89 (1998) 8. 
somos reconocidos, el que pro-voca nuestra reacción. "Son el rostro y los labios del otro el que llamándome me provoca" (P. Ricoeur). "Yo soy remitido al otro hombre para quien el llamarme tiene sentido" (Levinas). Existimos como humanos porque alguien (la madre principalmente) nos ha ido llamando. La gracia primera que recibimos no es el elegir, sino el haber sido elegido, no el acoger sino el ser acogido, no el llamar, sino el ser llamado. El "ser llamado", y precisamente por otros seres humanos, desde fuera, es un don que se nos hace y que nos hace ${ }^{8}$.

"El hombre no es un ser que pueda prescindir de los demás. Es un ser que, podríamos decir, muere en el contacto con su soledad. Encerrado en sí mismo pierde su ser. Es un error creer que puede construirse él solo y que el otro constituye necesariamente (aunque pueda constituirlo a veces) una agresión. La alteridad, se nos dice hoy -filosofías de la alteridad- es un factor constitutivo de la identidad. El otro es precisamente aquel que, por su misma alteridad, me llama, me convoca, me hace salir de mi propio encierro y de esta manera me permite acceder a mí mismo. El otro se convierte entonces para mí en gracia y salvación" ... "La alteridad, la exterioridad, no es una amenaza (Levinas). Alteridad (alter, el otro) no es sinónimo de alienación (alienus, enemigo, intruso)....". "Existimos (ex-sistere $=$ salir de la nada y del anonimato) porque hemos sido llamados por otro" 9 . Se trata, pues, como subraya el propio Gesché, de la conciencia de que la propia autonomía es siempre una "autonomía por la gracia de otro"10. La alteridad no se opone al anhelo de autonomía, totalmente legítimo, del hombre moderno y postmoderno, unicamente la orienta positivamente en la dirección adecuada, indica el camino para conseguirla, que es siempre el otro. La autonomía humana se construye desde el heteronombramiento. Y este, a su vez, nos remite hacia el otro y hacia el mundo. Todo llamamiento desemboca y entraña un éxodo. Y a la vez se convierte por sí mismo en envío, en misión.

8 Perspectivas y referencias en Roubinet, C., L'appel, Jeunes et Vocations, n.90 (1998) 5-13; Ver también García, J.A., "Soy llamado, por eso existo". La responsabilidad como hábito del corazón", Sal Terrae 83 (1995)19-30.

${ }^{9}$ Gesché, A., El destino. Sígueme, Salamanca 2001, pp.46.47.48.

${ }^{10}$ Ibíd.48. Las mismas perspectivas se encuentran desarrolladas también en su nueva obra El sentido, Sígueme, Salamanca 2003. 


\section{EI llamamiento, señal de amor: soy llamado, porque soy amado.}

Llamar a alguien, pronunciar su nombre, es fruto, signo y manifestación de afecto, de "buena voluntad". Llamamos a quienes queremos, en el doble y rico sentido del querer: porque nos "da la gana", por una decisión plenamente libre y totalmente gratuita de la voluntad; y porque "lo amamos", le "bien-queremos" (benevolencia). Al llamar a alguien le manifestamos nuestro aprecio, estima, reconocimiento y afecto.

Por esto el llamar solo es auténtico y legítimo cuando es desinteresado. Cuando no surge del deseo de poseer o conquistar, de dominar, de utilizar a alguien en beneficio propio, de reclutarlo para la propia causa, por noble o transcendental que se la suponga. Es auténtico y legítimo, en cambio, cuando y siempre que procede del deseo sincero de ayudarle a ser, de despertar o potenciar sus energías acaso dormidas, desconocidas o fragilizadas, de abrirle horizontes nuevos y amplios de vida, de orientación existencial, de proyección de energías en la construcción del futuro; cuando procede de la preocupación por él, por su crecimiento como ser humano, por su auténtica realización, por su genuina felicidad.

Porque es expresión de amor, el llamamiento va acompañado por la mirada, por el encuentro afectuoso de los ojos. La mirada manifiesta el corazón del que llama y descubre y revela el corazón del que es llamado. Es, por tanto, un encuentro más allá de las apariencias, un encuentro de corazones y en el corazón.

Por ello también todo llamamiento auténtico comporta una cierta "seducción". El que llama atrae al llamado, le incita a encontrarse, a "dejarse seducir". El llamar manifiesta el deseo de iniciar una alianza, de entrar en comunión de existencia y de proyecto con el llamadoamado, de hacerse "uno" con él, liberándolo así de la soledad, haciendo posible orientar la existencia hacia fuera de sí mismo, edificarse y realizarse a sí mismo en la trascendencia de sí.

La experiencia de ser llamado despierta en la persona una corriente de simpatía hacia sí mismo, hace posible el crecimiento de eso que hoy se llama su autoestima, la valoración positiva de sí mismo, el aprecio de su propio valer y de su profunda dignidad. Este reconocimiento y valoración promueve también un sentimiento profundo de 
seguridad. Así el llamamiento ayuda a superar las experiencias siempre traumáticas de esa "homologación" de que hablábamos antes, de considerarse a sí mismo como un simple número o miembro de una "manada", como algo sin nombre, sin valor, lo que es raíz y causa del desprecio de sí, fenómeno tan frecuente en nuestra sociedad y cultura antivocacional"1. "El yo moderno, -contra toda apariencia exteriortiene mucho de yo deprimido; no cree excesivamente -también contra toda apariencia- en sí mismo; teme su propio futuro. Pues bien, a un yo deprimido, sólo la llamada que le reconoce y le constituye puede ponerle en pie... Esa es nuestra "gloria", la base de nuestro ser, su principio pro-vocativo y dinamizador de respuesta, de responsabilidad"12.

Y esta será la experiencia que le enseña y le mueve a amar. Porque es bien sabido que sólo aprendemos y nos decidimos a querer, a desear y amar cuando y en la medida en que hemos experimentado, y lo experimentamos en el llamamiento, que hemos sido queridos, deseados, y amados 13 . "Yo no estoy seguro de ser amado por alguien más que si allí hay otro para decírmelo y para revelarme a mí mismo"14.

11 En una escena central de su novela La Ignorancia M. Kundera ha expresado con toda claridad y profundidad la presencia y el predominio de las relaciones "anónimas" en la sociedad actual, relaciones que pueden llegar hasta la intimidad sexual sin que en ellas intervenga "el nombre".

"De pronto (ella) se da cuenta: ijamás se ha dirigido a ella por su nombre!

-¡Tú no sabes quién soy!

-¡Cómo! -dice él de un modo desesperadamente torpe.

Ella le habla como un fiscal:

-Entonces, ¡dime cómo me llamo!

Él sigue callado.

-¿Cuál es mi nombre? ¡Dime cómo me llamo!

-¿Qué importan los nombres?

-¡Nunca me has llamado por mi nombre! ¡Tú no me conoces!

-¿Qué dices?

- ¿Dónde nos conocimos? ¿Quién soy yo?

Él quiere que se calme, la toma de la mano, ella le rechaza:

- ¡No sabes quién soy! (M. Kundera, La ignorancia, Tusquets, Barcelona, mayo 2000, pp.103-104.189-190-191).

12 García, J.A., Soy llamado, luego existo, Sal Terrae 83(1995)26-27.

13 Ibíd. 26.

14 A. Gesché, El destino, p. 48. 


\section{EI llamamiento, servicio a la libertad: soy llamado, y por eso me constituyo responsable.}

El llamar tropieza, en el presente contexto cultural, con un doble y acentuado obstáculo: el "respeto" cuasi sagrado de quienes podrían o deberían llamar por no condicionar la libertad de nadie; el temor y la sospecha de quien podría ser llamado de ser manipulado o forzado por la voluntad de otro, de vivir y obrar al dictado de alguien distinto de sí mismo ${ }^{15}$.

Pero la reflexión sobre la libertad humana, sobre su naturaleza y condiciones, ha ido dejando en claro no sólo que llamamiento y libertad interior del hombre no se excluyen, sino que no existe libertad auténticamente humana sin llamamiento, y que, por consiguiente, el llamar es un verdadero servicio a esa libertad.

El llamamiento, en primer lugar, no atenta a la libertad por cuanto, por su propia naturaleza y estructura, no es una imposición, sino una invitación, una propuesta. El llamar, puesto que y en la medida en que es invitación y propuesta, se sitúa en la raíz misma de la libertad, porque reconoce la capacidad de responder, la respeta, la estimula, la desafía (PDV 36). Y así se configura como el único procedimiento para suscitar seres libres, responsables. El hombre puede ser responsable sólo si tiene que responder, por tanto sólo si es libre. Pero a la vez, sólo puede ser libre si tiene que responder ante alguien que le llama. Cualquier otro sistema que pueda ser usado para influir en el hombre, como el empujar, fascinar, amedrentar, comprar, mandar, lo aliena y esclaviza.

La propuesta nunca es alienante porque no marca destinos ni constriñe a emprender rumbos. El hecho de llamar, como muy bien se ha dicho, "ha desfatalizado la historia", la ha instalado en la libertad16. El hecho de llamar a alguien procede de la convicción, y la proclama, de que la persona no tiene un destino fijado de antemano, que la fata-

15 Para todo este apartado puede verse: Guilbert, P., De l'autonomie a la liberté des enfants de Dieu, Jeunes et Vocations, n.58(1990)27-36; Huerre, D., De l'autonomie à la dépendance, Jeunes et Vocations, n. 90(1998)39-46. Las perspectivas que aquí se exponen se desarrollan muy adecuadamente por Simon, H., Appeler, c'est servir une liberté, Jeunes et Vocations, n.58(1990)7-25.

16 A. Gesché, o.c. pp. 39.44.165. 
lidad (el fatum) no es su herencia, que no existe un "destino inmutable e inevitable, al que el hombre debe simplemente adaptarse y resignarse en total pasividad" (PDV 37). Al llamarle se le anuncia la "buena nueva" de que en su propia entraña está el elegir y marcar el rumbo de su vida, que de él, de su respuesta, acogida o rechazo del llamamiento, depende la orientación de existencia.

El llamar, por otra parte, se coloca al servicio de la libertad humana en cuanto que ayuda a comprender su auténtico sentido. La libertad, en efecto, no consiste, como se pretende con tanta frecuencia, en hacer "la real gana", lo que en cada momento se le ocurre a cada uno. No es una "fuerza autónoma de auto-afirmación... en orden al propio bienestar egoísta" (FC 6) ni la "absoluta autonomía, pretendiendo que sea la única e inexplorable fuente de opciones personales y considerándola a toda costa como afirmación de sí mismo" (PDV 36). La afirmación de sí mismo, entendida como absoluta, es, como vimos, un error antropológico. Por otra parte, se manifiesta como un imposible la "pretensión" de ser uno mismo y solo la única fuente de sus opciones. Las decisiones humanas tienen siempre un alto grado de condicionamientos de tipo psicológico, educativo, cultural, se hallan siempre envueltas, estimuladas y enriquecidas por múltiples y variadas sugerencias, implícitas o explícitas, inconscientes o conscientes. El llamamiento se sitúa como una de esas sugerencias explícitas y enriquecedoras de la libertad de iniciativa.

El llamar ayuda también a la libertad en cuanto que la hace posible y precisamente en el nivel antropológico más hondo. La libertad, en efecto, no es la espontaneidad de dar rienda suelta a las propias pulsiones, de satisfacer los deseos de las necesidades, que en el fondo esclavizan. La palabra que llama desde fuera, precisamente porque no brota de los deseos o desde el anhelo de satisfacer las propias necesidades, cumple la función, como se ha formulado en términos paradójicos, de ser como un "entre-dicho" (inter-dit) (Lacan, Levinas), un "dicho" que se coloca "entre" las necesidades y el "yo", y, al interponerse, se opone a la esclavitud que aquellas ejercen despóticamente sobre las decisiones del yo, le obligan a definirse, a sobreponerse y a liberarse de la alienación a que los deseos lo someten.

El llamamiento sirve a la libertad también provocándola, salvándola de la indefinición y de la indecisión. Cuando alguien no escucha 
nunca su nombre pronunciado por otros labios, cuando experimenta que nadie le dirige su palabra, vive encerrado en su soledad y en la angustia, que le paralizan, en su postración que le impide caminar, definirse y decidirse. La palabra que se le dirige le ayuda a levantarse, a "tomar su camilla" y a caminar, a recorrer rutas personales, a dar rumbos nuevos a su existir, le ayuda, por tanto, edificarse, a construirse en libertad. Es verdad que, por su carácter de sugerencia, el llamar no cultiva la "libertad de iniciativa" pero sí provoca la "libertad de consentimiento" y la "libertad para", muy especialmente la "libertad para entregarse", la más genuinamente humana, "libertad que en la respuesta positiva se cualifica como adhesión personal profunda, como adhesión de amor... esto es, como oblación" (PDV 36), "principio y fuerza del don responsable de sî" (PDV 37).

El llamar cultiva y sirve a la libertad también por cuanto abre horizontes, despierta posibilidades, sugiere orientaciones, anima y estimula energías acaso dormidas. La experiencia humana indica que la palabra de otro es la que nos revela nuestros deseos más genuinos escondidos muchas veces bajo los anhelos de satisfacer puras necesidades alienadoras. "En el origen de las aventuras humanas (artísticas, deportivas, sociales...) se encuentra casi siempre el empuje de un llamamiento que ha sido una revelación para la propia persona que 10 recibe. Ha habido una revelación para pasar de una espera difusa, a veces angustiosa, siempre incierta de sí misma y de sus fines, a una visión clara y determinada de aquello que se convirtió después en el eje mayor de toda una vida"17. El llamamiento hace posible y pensable el responder a algo en lo que acaso nunca se había pensado, en lo que acaso se imaginaba que no era posible para él. De esta manera, se le libera de los estereotipos ambientales que le impedía pensar en otras posibilidades de existencia y de acción.

Finalmente, hay que subrayar que el llamamiento, aunque procede del exterior, nunca se mantiene como una realidad puramente extraña. Nada más oírlo, se convierte en interpelación, en reclamo a y ante la propia conciencia. La voz exterior que llama solo adquiere sentido y se escucha genuinamente cuando se interioriza y se discierne y juzga en el punto más íntimo de la propia conciencia. Si se acoge, si se acepta, si se responde, es porque resuena en sintonía profunda con lo más íntimo de cada uno. Y así lo exterior se hace íntimo, lo ajeno, propio, 
lo extraño, entrañable. La voluntad no se siente en modo alguno forzada, constreñida, manipulada. "Mediante el asentimiento interno la libertad es capaz de asimilar lo que primeramente parecía "externo" y opuesto, y de constituir con ello -a un nivel más elevado- la communio entre lo "externo" y lo "propio"18.

\section{PERSPECTIVAS BIBLICO-TEOLÓGICAS: un pueblo de "llamados por el propio nombre"}

"Que toda la existencia del hombre sea una vocación no lo hemos aprendido a fuerza de reflexiones filosóficas o religiosas. Lo hemos comprendido escuchando y amando la narración de la vida y de las enseñanzas de algunos hombres que Dios escogía para sî"19, de hombres que se entendieron a sí mismos, en la entraña constitutiva de su propio "yo", como un "sujeto convocado" 20.

La aplicación de esta conciencia de llamamiento, sin embargo, se realiza primariamente en referencia a todo el conjunto del pueblo de Dios, conciencia que quedará plasmada en el nombre mismo de "iglesia", ek-klesía, la asamblea de los con-vocados, de los llamados por Dios para formar "su" pueblo, para ser conocidos por su nombre, para invocar y santificar su nombre. "La vocación define, en cierto sentido, el ser profundo de la Iglesia, incluso antes que su actuar. En el mismo vocablo de Iglesia (Ecclesia) se indica su fisonomía vocacional íntima, porque es verdaderamente "con-vocatoria", esto es, asamblea de los llamados: "Dios ha convocado la asamblea de aquellos que miran en la fe a Jesús, autor de su salvación y principio de unidad y de paz, y así ha constituido la Iglesia, para que sea para todos y para cada uno el sacramento visible de esta unidad salvífica" (LG 9). "Una lectura pro-

17 H. Simon, Appeler, c'est servir une liberté, Jeunes et Vocations, n.58(1990), p.8.

18 G. Greshake, Ser sacerdote hoy, Sígueme, Salamanca 2003, p.166.

${ }^{19}$ Sicari, L., La vocación de los profetas, en Favale, A., Vocación común y vocaciones específicas, Vol. 1, Aspectos bíblicos, Atenas, Madrid 1984, p.162.

${ }^{20}$ Es el título de una conferencia de P. Ricoeur en que expone de manera magistral esta perspectiva: Le sujet convoqué. A l'école du recit de vocation prophétique, en Revue de L'Institut Catholique de Paris, oct-dez.(1988)88-99. 
piamente teológica de la vocación... puede nacer solo de la lectura del misterio de la Iglesia como mysterium vocationis" (PDV 34).

En un estadio posterior, a partir de la conciencia personal de los profetas, esa condición de "sujeto convocado" se extenderá a todos y cada uno de los incorporados al pueblo de Dios e incluso, en un alarde de un arriesgado y admirable coraje teológico, a todos los hombres que vienen a este mundo. Esta conciencia hallará su síntesis más explícita en la fórmula "llamados por el propio nombre".

1. Llamados por el propio nombre. La expresión "llamar por el propio nombre", con Dios como sujeto, y referida a personas concretas, no es muy frecuente en la Biblia, -solo 8 veces: dos en el Éxodo, 6 en el segundo y tercer Isaías, y 2 en el evangelio de S. Juan ${ }^{21}-$ pero es extraordinariamente rica y significativa en su aplicación y alcance.

La fórmula se aplica, en el Éxodo, a Besalel, un "orfebre" muy experto en su profesión (cfr. Ex 31,2; 35,30). En Isaías, se refiere, en primer lugar, al pueblo-siervo: "Así dice el Señor, el que te creó, Jacob, el que te formó, Israel: no temas, que yo te he rescatado, te he llamado por tu nombre y eres mío" (Is 43,1; cfr. Is 48,12); en segundo lugar, a la Jerusalén restaurada: "te pondrán un nombre nuevo pronunciado por la boca del Señor" (Is 62,2); en tercer lugar, al siervo de Yavé, en su condición de figura individual: "El Señor me llamó desde el seno materno, desde las entrañas de mi madre pronunció mi nombre"(Is 49,1); finalmente, y por dos veces, con toda solemnidad, y sin escrúpulo alguno, al rey persa Ciro, "liberador" del pueblo del exilio de Babilonia: "Por amor a Israel, mi elegido, te llamé por tu nombre, te di un título, aunque no me conocías" (Is 45,4); "yo en persona le hablé y lo llamé, yo lo he traído y tendrá éxito" $(48,15)$. En el NT, la fórmula se aplica a las "ovejas" que el "buen pastor" conoce y llama por su nombre (Jn 10,3.14). Esta múltiple referencia -a un "profesional" en el ejercicio de su profesión, al pueblo en su conjunto, a uno de sus miembros, aunque significativo, y, sobre todo, a alguien ajeno a dicho pueblo- autoriza a extenderla y aplicarla a todas y cada una de las personas que vienen a este mundo.

${ }^{21}$ No incluimos la referencia del Salmo 146,4 e Is. 40,26 , porque no se refieren a personas sino a las "estrellas", en un sentido, por tanto, claramente metafórico, derivado. 
El alcance y riqueza de la expresión se percibe si tenemos en cuenta los aspectos fundamentales de "la teología bíblica del nombre". En la Biblia, en efecto, como en todo su entorno cultural, "el nombre, lejos de ser una designación convencional, expresa... el papel de un ser en el universo. Dios da cima a la creación poniendo nombre a todas las criaturas (cfr. Gn 1,3-10), designando a cada uno de los astros por su nombre (cfr. Is 40,26), o encargando a Adán dar nombre a cada uno de los animales (cfr. Gn 2,20)"22.

En primer lugar, el nombre, de ley ordinaria, alude a la identidad, "enuncia algo esencial o típico acerca del que lo lleva. El nombre de Jesús es interpretado así expresamente en Mateo (1,21.25; cfr. Ecco 46,1)"23. Expresa, si no la identidad sí "la importancia, la eficacia y el "poder" del portador del nombre" de ordinario manifestado en su vida e historia", es, por lo mismo, "el exponente de la personalidad"24. El nombre indica el "sentido de una vida" según Dios, la "orientación o el destino" de la persona, el "papel", la "nueva identidad dinámica", lo que está llamado a ser y/o a realizar. Esto es lo que se advierte no solo en los numerosos casos de "imposición del nombre" (cfr. Lc 1,31; 2,21; Mc 3,16; Os 1,6.9) sino sobre todo en el "cambio de nombre" (cfr. Gn 17,5.15: Abram-Abrahán/Sarai-Sara 32,29: Jacob-Israel; Mt 16,18: Pedro-Kefas)."Cuando Jesús da a alguien un nombre nuevo le concede con ello graciosamente una nueva identidad (cfr. Mc 3,16s; Ap 2, 17; cfr. Jn 10, 3)"25.

El cambiar el nombre indica asimismo un ejercicio de poder sobre la persona (cfr. Mc 5, 9). "Actuar sobre el nombre es tener influjo en el ser mismo... Esto indica también que quien cambia el nombre toma posesión de su vida"26. "El hecho de cambiar el nombre se funda en el "derecho de soberanía que ejerce el que cambia el nombre sobre la persona a la que se le cambia... El modo de percibir este derecho de

${ }^{22}$ Dupont, J., art. Nombre en VTB.

23 Hartmann, voz onoma/nombre en DICCIONARIO EXEGÉTICO DEL NUEVO TESTAMENTO (DENT), Sígueme, Salamanca 2004.

24 Voz shem/nombre, en JENNI, E WESTERMANN, C., Diccionario Teológico Manual del Antiguo Testamento (DTMAT), Cristiandad, Madrid.

25 Cfr. a.c., en DENT.

26 A.c. VTB. 
soberanía puede ser distinto, dado que puede implicar dominio, incluso explotación de aquellos a quienes se da o se cambia el nombre, o un compromiso de protección"'27.

El nombre, además, puede expresar el potencial social de una persona, "hasta el punto de que "nombre" puede significar también "renombre" (cfr. Nm 16,2)"28. Así san Pablo puede afirmar solemnemente que "el nombre de Jesús es un "nombre sobre todo nombre..." (cfr. Flp 2,9; cfr. Ef 1,21; Heb 1,4). "Se adquiere un nombre en el sentido de prestigio cuando se acrecienta la propia gloria (kabod) por medio de grandes acciones y riquezas"29. "Con el nombre se conoce la reputación de una persona" (Mc 6,14: el nombre -fama- de Jesús se había extendido...) $)^{30}$. "El nombre, en sentido dinámico, designa "el compendio de las acciones y obras, del poder y del prestigio de un hombre. Por ello,... shem/nombre como "exponente de la personalidad" no significa solo descendencia (Is 66,22), o "propiedad" (Nm $27,4)$ sino ante todo (como en algunas lenguas modernas) "honor, gloria, fama" (cfr. Dt 26,19; Jr 13,9.11)"31.

El nombre es también instrumento o medio de comunicación. Por eso para conocer el nombre de Yavé es preciso una automanifestación suya (cfr. Ex 3,13.15). "El conocimiento del nombre capacita para la comunicación: si se conoce el nombre de una persona, o de un dios, se le puede hacer venir, "citar". En este sentido, el conocimiento del nombre significa, hasta cierto punto, un poder sobre la persona conocida"32.

2. La fórmula bíblica "llamar por el propio nombre" reúne, sintetiza y acentúa el contenido del "llamar" en su dimensión antropológica así como el de la "teología del nombre", con lo que las perspectivas teológicas y espirituales del llamamiento adquieren una hondura y alcance sorprendentes.

\footnotetext{
27 a.c. DTMAT.

28 a.c.,VTB.

29 a.c, DTMAT.

30 a.c. DENT.

31 a.c. DTMAT.

32 a.c. DTMAT.
} 
a) En primer lugar, "llamar por el propio nombre" constituye y designa el acto originante del existir humano contemplado desde la relación con el sujeto del llamamiento, el Dios que pronuncia el nombre. "Del mismo modo que en un plano antropológico son los tús humanos y los contextos culturales los que, dirigiéndose hacia nosotros, llamándonos, nos hacen existir como humanos, así también es la llamada de Dios la que nos posibilita la existencia, la fe y el seguimiento creyentes" 33 .

En el caso de BESALEL, el artista, el ser llamado por su nombre presenta sus cualidades y capacidades como fruto de una peculiar destinación, y da a su arte la trascendencia de un servicio a lo divino.

Referido al PUEBLo, le da existencia e identidad porque lo hace salir de la situación de anonimato a la que estaba condenado en el destierro, de diluirse entre los otros pueblos, de haberse convertido en " $\mathrm{a}$ morfo", sin su "forma" propia como "pueblo de Dios". Al ser llamado por su nombre el pueblo se sabe re-creado, salido de la nada, enderezado de nuevo graciosamente en su peculiar orientación en la historia según el proyecto de Dios, en favor de los otros pueblos (pro-existente), consciente de su con-sistencia como pueblo y como pueblo de Dios.

Referido al SIERVO, proclama su identidad y existencia acentuando sobre todo la gratuidad cuando se afirma que el llamamiento acontece "desde el seno materno", desde las entrañas maternas".

El llamamiento dirige la existencia y orienta la acción histórica de Ciro, le otorga "éxito y título", "renombre", le da existencia como "liberador", lo saca de la nada, de lo anodino y de lo amorfo de su propia historia introduciéndolo en la historia de Dios con su pueblo, en la "historia de salvación".

b) En segundo lugar, llamar por el nombre indica que, cada persona del pueblo de Dios, representada tanto en la figura de Besalel como sobre todo en la típicamente representativa de el Siervo, y aun aquella que no pertenezca al pueblo, "que no conozca" al llamante, como es el caso del persa Ciro, es un ser conocido en su propia peculiaridad y considerado como alguien único, original, diferente de cual-

33 García, J.A., a.c. 26. 
quier otro, valioso en sí y por sí mismo, y no como un número o una pieza anónima de un engranaje social, político o religioso. Llamar por el nombre saca de la marginación, de la desconsideración, de la "invalidez", de la postración, y, por lo mismo, provoca el "dar un salto", el "ponerse en pie", como en el caso del ciego Bartimeo al saber que Jesús le llama (cfr. Mc 10,48-52). Esto provoca un profundo sentimiento de alegría, una valoración positiva de sí, una conciencia clara de su profunda dignidad, una alta estima y consideración de su valer a los ojos del que llama y por lo mismo ante sus propios ojos.

c) El "llamar por el nombre" crea lazos de pertenencia. No la pertenencia de dueño-esclavo, de superior-inferior, de jefe-súbdito, sino la pertenencia mutua de quien se ofrece y es aceptado, de quien se entrega y halla acogida, de quien da y es recibido (cfr. PDV 36), de quien bate a la puerta y comprueba que se le abre. El llamamiento provoca relaciones de alianza.

La "pertenencia" está cargada de afecto, de cordialidad, de "querer", de ternura incluso. Este es el matiz más marcado en los textos en que aparece la expresión literal "llamado por tu nombre", pues dicha expresión va acompañada, completada y explicada con estas frases: "te he tomado de la mano" (Is 45,1), "te tomé de la mano, te formé, mi elegido en quien me complazco" (Is 42,1.6); "tú vales mucho para mí, eres valioso y yo te amo" (Is 43,4); "Tú eres mi siervo, estoy orgulloso de ti" (Is 49,3).

"Llamar por el nombre" se convierte así en la expresión primera y primaria del amor, en la que resuena, por otra parte, la experiencia primaria del llamamiento, la de la madre y su ternura: "Aunque una madre se olvide, ... yo no te olvidaré (Is 49,16); y, de alguna manera también, la del enamorado que lleva tatuado el nombre de la amada en su propio cuerpo (Is 49,1).

La ternura, el afecto y la entrega mutua caracterizan y se descubren si cabe con mayor intensidad en el "llamar por el nombre" del pastor a sus ovejas y el "conocerse mutuamente" (Jn 10,3.14), que indica la pertenencia mutua y la relación profunda e íntima de amor, de amistad (cfr. Jn 15,15), entre Jesús y los suyos.

Otros textos del NT en que aparece el llamar y el nombre confirman y acentúan esta perspectiva. Baste aludir al "llamó a los que quería", referida al llamamiento por su propio nombre de Los 12 (Mc 
3,13-18). "Jesús sube al monte y "llama (proskaleitai) a los que quería (ethelen) y fueron (apelthon) donde él.... Jesús "llama"... Cuál es el contenido de este verbo?... Jesús pronuncia en voz alta los doce nombres, les hace señas y ellos se separan de los demás y van hacia él. Exteriormente es pronunciar detalladamente y con solemnidad algunos nombres. Pero desde el punto de vista de las actitudes este verbo tiene claramente la idea de subordinación. De este modo llama quien tiene poder sobre otro (cfr. Mc 15,4: Pilato llama al centurión...). Probablemente además de la idea de subordinación está la de preferencia: una relación especial con Jesús inserta en este llamar que elige. En todo caso la preferencia es clarísima en el versículo siguiente: "los que él quería": aquí se expresa la soberanía de la llamada. Más aún, a este "quería" no se le debe atribuir sin duda solo la idea de "aquellos que le gustaban a él", "a los que se le ocurrió", sino más bien la idea del verbo hebreo "a los que él tenía en el corazón" (cfr. Mt 27,43). Jesús, pues, llama a los que "él" (autós) quiere, a los que tiene en el corazón, a los que ama. El autós... subraya que no hay ninguna cualidad, ninguna belleza o atracción por parte de quien es 1lamado, sino que es Jesús quien los ama y elige. Este amor suyo es el motivo de sus acciones. Tal vez pueda leerse otro matiz en el imperfecto "que quería", "que amaba, es decir, la intensidad del afecto (cfr. Mc 6,19, donde con el mismo verbo, tiempo y modo, se alude a la intensidad de la pasión de Herodías contra el Bautista). Aquí... Jesús tiene en el corazón a los suyos, con amor apasionado. Él mismo, pues, los llama"34.

El mismo sentido, cargado de mayor intensidad y afectuosidad si cabe, se descubre en el "llamar por el nombre" del pastor a sus ovejas y el "conocer" mutuo del pastor a cada una de ellas (Jn 10,3.14). "La voz de Jesús es un mensaje que significa liberación (cfr. 8,12). Su voz no se dirige a una multitud anónima, es una llamada personal: las llama por su nombre. No existe la masa para Jesús (cfr. Jn 6,10), cada uno tiene rostro y nombre... La expresión (que se usa más tarde, 10,14-15) conozco a las mías y las mías me conocen, indica la relación de amor entre Jesús y los suyos" 35 .

\footnotetext{
${ }^{34}$ Martini, C.M., Evangelio y comunidad cristiana, Paulinas, Bogotá 1992, pp.48-50.

${ }^{35}$ Mateos, J.-Barreto, J., El evangelio de Juan, Cristiandad, Madrid 1979, pp.464.469.
} 
Más tierno aún se muestra Jesús al llamar por su nombre, después de la resurrección, a María, la de Magdala, y en la respuesta de ella al pronunciar el "nombre" nuevo del Resucitado (Jn 20,16). La escena en el huerto-jardín, los apelativos previos "señor-mujer", que equivalen a "marido-esposa", y que remiten sin duda al Cantar de los Cantares, y, a su vez, a la primera pareja de la humanidad, Adán-Eva en el paraíso, carga la escena de extraordinaria fuerza afectiva. "Jesús la llama por su nombre (cfr. 10,3) y ella lo reconoce por la voz, aunque no lo había reconocido por la vista. Este tema aparece también en el Cantar (cfr. 5,2 ). Al oír la voz de Jesús y reconocerlo... La respuesta de María "rabbunî", Señor mío, tratamiento que se usaba para los maestros, pone este momento en relación con la escena donde Marta dice a su hermana: El maestro está ahí y te llama $(11,28)$. Por otra parte, aunque los términos "Rabbi" y "Rabbunî" sean prácticamente sinónimos (Señor mío), el segundo... es el punto de llegada (después de la resurrección), después que su enseñanza ha culminado dando su vida en la cruz: Jesús es maestro de un modo nuevo... Al mismo tiempo Rabbuni podía ser usado por la mujer dirigiéndose al marido. Se combinan así los dos aspectos de la escena: el lenguaje nupcial expresa la relación de amor que une la comunidad a Jesús; pero este amor se concibe en términos de discipulado, es decir, de seguimiento: se corresponde a su amor practicando un amor como el suyo $(1,16 ; 13,34)^{36}$.

De nuevo encontramos este matiz afectivo, y en unos términos que acentúan la profundidad y la trascendencia del afecto, en la escena final del evangelio, en el llamamiento a Simón (Pedro) y la encomienda del pastoreo y la confirmación del seguimiento (Jn 21,15-19: Simón, hijo de Juan, me amas... Sí, Señor... le dijo: Sígueme"). Jesús se dirige a Simón no por su nombre nuevo, Simón Pedro, sino por su "nombre propio", Simón de Juan (v. 15b). La pregunta por el amor, y la respuesta de Simón, habla de una relación no de liderazgo, no de superior que se impone $(13,5.14)$, no de señor que domina, sino el amigo de los suyos (cfr. 15,15). "El apacentar-pastorear significa la entrega del discípulo". "Los términos usados en este pasaje: corderos, ovejas, lo ponen en relación con 10,1ss. La condición para encontrar

36 Id.pp.855-856. 
pasto es "entrar por la puerta", que es Jesús $(10,9)$, es decir, seguir su modo de actuar prestando servicio hasta la muerte. Procurar pasto o alimento es comunicar vida, y esto solamente puede hacerse estando dispuesto a darlo todo $(12,24) .$. Al repetir el evangelista la pregunta de Jesús: ¿me quieres?, muestra su importancia. Hay adhesiones que no son las que él pide; Pedro se la había mostrado como a líder; pero esto no respondía a lo que es Jesús ni a su programa. Era la adhesión del que renuncia a su libertad para ponerse a las órdenes de un jefe. La que pide Jesús es la que da libertad, por fundarse no en la subordinación, sino en la amistad"37.

d) Llamar por el nombre manifiesta la confianza que el que llama tiene en el llamado, confianza en él como persona, en su capacidad y en su "buena voluntad" de responder, de iniciar una relación con él.

Esto despierta en el 1lamado, por una parte, la conciencia de su libertad para responder, la conciencia de su responsabilidad, de lo que está en juego también si rechaza al que llama y rehúsa lo que éste le sugiere o propone. $\mathrm{Y}$, por otra, una profunda seguridad y confianza en sí mismo, al saberse objeto de la confianza del que pronuncia su nombre. El llamar, por tanto, es un estímulo, desde dentro, a hacerse y ser "digno del nombre que le han dado". Esto orienta la existencia hacia la coherencia y la autenticidad. "Si llamamos "autenticidad" al ideal humano de ser "uno mismo", y "responsabilidad" a la cualidad, también humana, de "responder" a quien se dirige a nosotros... no hay autenticidad sin responsabilidad; la responsabilidad es un "momento interior" de la autenticidad... Habría que decir que para ser uno mismo hay que tomar en serio a los otros y a lo otro distinto de uno. Hay que responderles. Sin responsabilidad, es decir, sin respuesta a aquello o a aquellos que le constituyen a uno, no es posible la autenticidad"38.

e) Ser llamado apela a ponerse a disposición del que pronuncia el nombre, hace solidario con él, con su causa. La respuesta primera a quien pronuncia el nombre es: "Sí, aquí estoy"... (Adsum, hinneni, Presente), qué quieres de mí (Hch 9,6, Pablo), por qué y para qué me 1la-

37 Id. o.c. pp. 909.917.

38 García, J.A., a.c. 21-22. 
mas (cfr. Gn 22,1; 46,2; Ex 3,4), "hágase" (Lc 1,38), "qué mandáis hacer de mí" (Santa Teresa). Con ellas se expresa la disposición, inicial al menos, para salir al encuentro del que llama, escuchar sus preocupaciones, planes o proyectos, y colaborar con él en su realización, entrar en comunión con su voluntad, y, por tanto, obedecer (ob-audire). Y, si, consciente del nombre con que es agraciado por el llamamiento, del don que se le hace, acepta el riesgo de caminar con quien se lo ha otorgado, emprende con él lleno de confianza y de gratitud el camino sugerido y lo recorre con él cantando (cfr. el Magnificat).

f) El llamar por el propio nombre proporciona también un cierto nivel de relevancia. No es la relevancia o el renombre que procede del tener. Ni la relevancia que procede del hacer, del cargo, profesión o actividad. Ni la relevancia del saber. No es la relevancia del que se siente "privilegiado", o preferido, que le lleva a "vanagloriarse", a considerarse superior a todos, a despreciarlos, a dominarlos. Es la relevancia del nombre "que le ha sido dado" "antes de ser concebido en el seno materno", antes, por tanto, de cualquier deseo o anhelo salidos de sí mismo. Es la relevancia que entraña siempre una des-apropiación, un éxodo, un ser encargado y cargado con una misión que procede de otro, de la que ese otro es protagonista y garante, que se realiza en favor de los otros, los elegidos por aquel que llama39.

39 Puede traerse aquí a colación la posibilidad que el adulto tiene de darse a sí mismo un nombre nuevo con motivo del bautismo. Tenemos un ejemplo ilustrativo en lo que hizo Pablo cuando cambió su nombre de Saulo para Pablo, cfr. Hch 13,9: una historia bien curiosa y significativa. Se explica el significado del nombre de Elimas (el mago). Saulo consigue eliminar su influencia sobre el procónsul Sergio Pablo, que se convierte, y a continuación se dice: "Saulo, llamado también Paulo". El cambio de nombre, que no se explica, parece querer indicar que asume el nombre de su primer éxito apostólico entre los griegos, y en ello ve el signo de su misión posterior, el apóstol de los gentiles. A partir de ahí nunca más vuelve a aparecer su nombre de familia, sino el de la misión .

En este sentido habría que recordar también el valor "teológico-espiritual" de el "cambio de nombre" que se realizaba al profesar en la vida religiosa antes de convertirse en exigencia del Ritual, o de ser impuesto un nombre cualquiera por los superiores sin tener en cuenta la aspiración de identidad del que iba a llevar el nombre nuevo. De alguna manera hacía visible el "nombre propio", peculiar, específico, que se daba a sí mismo el sujeto, lo que él quería vivir-significar en la nueva etapa de su vida como consagrado. Baste recordar el denominativo "de la Santa Faz" en Teresa del Niño Jesús, o el de Teresa "de Jesús", de la santa de Ávila. 
3. "Llamados por el propio nombre" por la Iglesia en nombre de Dios: dimensión eclesial del llamamiento.

El llamamiento es primeramente una experiencia humana, la de una lengua y unos labios que pronuncian un nombre en voz alta, de manera que pueda resonar en los oídos del llamado. El verbo hebreo (qarah) y sus correspondientes griego (kaleo) y latino (vocare) designan, en sentido propio, una voz, un sonido, en tono alto, audible, casi como un grito. La "con-vocatoria" que da lugar a la reunión del pueblo, la ek-klesía, es una convocatoria pública, oficial, de viva voz.

Así ocurre en el llamamiento de los discípulos por parte de Jesús. Lo que ellos oyen es una voz humana, percibida por sus oídos. "Jesús "llama" (proskaleitai)... ¿Cuál es el contenido de este verbo? Jesús pronuncia en voz alta los doce nombres... Exteriormente es pronunciar detalladamente y con solemnidad algunos nombres ${ }^{40}$. Es una voz humana, "con autoridad", pero nada indica que en ese momento esa autoridad se identifique con una voz venida del cielo, con la voz de Dios. Todo parece indicar, como dice el Card. Martini, que es ya una representación de una verdadera elección eclesial: "Jesús está junto al lago... la gente lo sigue, y después, desde esa posición elevada, comienza a gritar, a llamar por el nombre. Se trata, pues, de una verdadera elección eclesial, en un cierto sentido... Jesús, sin separarse de la muchedumbre, pero distanciándose en cierto modo... abrazándola con una mirada, llama a Los Doce. No los elige en la soledad, los elige en su plena actividad, de entre la muchedumbre que busca su ayuda. El sentido apostólico y eclesial de esa elección queda evidenciado por el mismo modo de la descripción"41.

Así ocurre también con las que podríamos llamar las "primeras vocaciones eclesiásticas". La elección y el llamamiento se hace por voces de hombres, por procedimientos humanos, como en el caso de Matías (Hch 1), en la elección de Los Siete (Hch 6), en la designación de los presbíteros en las iglesias de Asia por parte de Pablo y Bernabé (Hch 14,23), en las de Timoteo y Tito por parte de Pablo (cfr. Hch 16,3;

40 Martini, C.M., o.c. 48.

${ }^{41}$ Id. Ibíd. 
2 Tim 1,6; Tit 1,5). Y porque han de ser realizadas por hombres se ofrecen instrucciones abundantes y precisas para el llamamiento de los epíscopos, presbíteros y diáconos en las cartas pastorales.

\section{El Bautismo, como experiencia primaria de llamamiento}

La primera experiencia, y la primaria, del llamamiento eclesial, modelo y fuente de cualquier otro llamamiento, la constituye el bautismo.

Así aparece en la liturgia del bautismo de adultos, hoy felizmente recuperada, y que expresa clara y explícitamente la convicción de la Iglesia de ser ella la que llama, que es su voz la que resuena, aunque lo haga convencida de que por su medio es Dios quien elige, invita y llama.

Así se afirma en las Observaciones previas del Rito de admisión de los catecúmenos: "En este grado hace la "elección" la Iglesia... Se llama "elección" porque la admisión, hecha por la iglesia, se funda en la elección de Dios, en cuyo nombre actúa la iglesia" (n. 22). El primer acto del Rito de entrada en el catecumenado consiste en que el celebrante "llama a cada uno por su nombre", los llamados responden "Presente", y expresan su deseo de "entrar en la Iglesia", o de recibir "la gracia de Cristo", o "la vida eterna" (n. 75). En el Rito de la elección o inscripción del nombre se incluye la deliberación de la comunidad eclesial: "La elección es como el centro de la atenta solicitud (de la iglesia) hacia los catecúmenos... Conviene que antes se tenga alguna deliberación sobre la idoneidad de los candidatos por aquellos que les atienden" (n. 137). "Es oficio del celebrante... exponer ante los presentes la decisión de la iglesia... y efectuar, por último, en nombre de Cristo y de la iglesia, la admisión de los "elegidos" (n. 138).

En el primer acto de la Celebración del rito los bautizandos son designados como "los que han de ser elegidos" e inmediatamente "se les va llamando a todos por su nombre" (n. 143). En el interrogatorio posterior se afirma: "la Iglesia, confiando en este sufragio (el testimonio positivo de los padrinos y catequistas) os llama en nombre de Cristo a los sacramentos pascuales. Ahora, pues, os toca a vosotros... dar vuestra respuesta en presencia de la Iglesia..." (n. 146), diciendo cada uno su propio nombre. El rito de admisión o elección se realiza con esta 
fórmula: "N., has sido elegido..." (n. 147), y en la oración que sigue se invoca al Señor para que se digne guiar "a estos elegidos de la Iglesia", elección que se identifica con "la vocación recibida" (n. 149).

En las Oraciones de los escrutinios alternan las designaciones de "elegidos de Dios" con las de "a los que eligió la Iglesia..." (nn. 162.163.169.170.171.176.177). En la oración después de la entrega del símbolo, se les denomina "nuestros elegidos" (n. 187), lo que se repite después de la entrega de la oración (n. 192) y en la oración para la recitación del símbolo (n. 198).

A esta experiencia bautismal aludirían, al menos según muchos comentaristas ${ }^{42}$, las expresiones fundamentales sobre la vocación cristiana que aparecen en los libros del NT, como cuando los cristianos son designados como los "elegidos" (Col 3,15), objeto de una "elección" y/o "vocación santa" (1 Tes 2,12; 2 Pe 1,10; 1 Tim 1,9; 1 Cor 7,20; Ef 4,1), los "llamados de Dios" (cfr. Rom 8,30; 1 Pe 1,15; 2,19); o expresiones como la de que "Dios nos llamó por medio del evangelio" (2 Tes 2,14), o la del intento de explicación teológica de las fases de dicha "vocación" que aparece en la Carta a los Romanos: "a los que predestinó, a ésos también los llamó" (Rom 8,30).

Los términos, pues, de "elección", "llamada", "vocación", se aplican, en el sacramento fundante de la identidad cristiana, primariamente a la acción de la iglesia, acción que, por su parte se comprende como el medio por el que Dios actúa su propio llamamiento, en el nivel íntimo, previo, trascendente, que le es propio.

2. Un llamamiento específico: llamar por el propio nombre para el ministerio ordenado

El llamamiento por el propio nombre realizado por la Iglesia, que acontece en el bautismo, se halla presente, de manera más o menos clara, en todas y cada uno de las acciones sacramentales, o cuasi sacramentales, en las que se concretizan las diferentes "modalidades" o vocaciones específicas del existir cristiano, y muy especialmente en la

\footnotetext{
42 Puede verse en este sentido el artículo Llamar en el ya mencionado Vocabulario Bíblico, dirigido por Von Allmenn.
} 
vocación peculiar para el ministerio ordenado, el de los obispos, presbíteros y diáconos.

La liturgia de la ordenación, como la del bautismo, muestra con toda claridad la dimensión eclesial de la vocación, es decir, el llamamiento por el propio nombre por parte de la iglesia en el nombre del Señor.

El Rito de ordenación comienza con el llamamiento por el propio nombre y con la petición hecha por la Iglesia de ordenar al que es objeto de ese llamamiento, petición a la que el obispo responde: "Elegimos a este hermano nuestro para el orden de...". Esta fórmula manifiesta con toda claridad que es el Obispo, y por su medio, la Iglesia, la que "elige", que la elección es, por tanto, obra humana. En las fórmulas siguientes alternan, también como en el bautismo, las expresiones "estos elegidos nuestros" con "estos elegidos de Dios". La "lex orandi", pues, del rito de ordenación, tanto de los obispos como de los presbíteros y de los diáconos, atestigua que la elección o la vocación consiste en el llamamiento de la iglesia y que, por lo tanto, no se puede identificar con la "aspiración" o "candidatura" del ordenando, con su deseo, fruto de un sentimiento interior o de la convicción subjetiva de haber sido llamado directamente por Dios, del que la Iglesia sería solo y a lo sumo testigo o garante.

La conciencia de esta dimensión eclesial del llamamiento para la ordenación aparece ya desde los primeros testimonios cristianos sobre la ordenación (por ejemplo, La Tradición Apostólica, de Hipólito).

Esta conciencia inspiró la praxis de la elección en la iglesia antigua, donde es bien conocido el fenómeno de los ordenados sin pretenderlo (invitus) y presionados u obligados (coactus) ${ }^{43}$, la huída ante la ordenación, el hecho de ser considerada inválida la de aquellos que fueran ordenados sin la petición o el llamamiento de la iglesia ${ }^{44}$. Esta

43 Aspecto este muy bien conocido y ya ampliamente estudiado. Puede verse en especial: CONGAR, Y.-M., Les ordinations "invitus", "coactus" dans l'Église antique, Recherches de Sciences Philosophiques et Théologiques 50(1956)167-197; FERET, H.M., Vocations, Vie Spirituelle 446(1959)64-72; LEGRAND, H., La teología de la vocación al ministerio ordenado: ¿vocación o llamamiento? Seminarios 46(2000)431-452 (original francés en VS 729(1998)621-640). 
conciencia se ha formulado y proclamado en los concilios, se ha enseñado en los Catecismos, como en el de Trento que afirma: "Son llamados por Dios sólo aquellos a quienes llaman los legítimos ministros de la iglesia" (Parte III, De ordine, 3). Fue ratificada en 1912 por Pío $\mathrm{X}$ al aprobar una Comisión Cardenalicia la obra del Canónigo Lahitton, el cual, en una polémica famosa con Blanchereau, defendía que "nadie tiene ningún derecho a la ordenación anteriormente a la libre elección del obispo", que la "vocación sacerdotal no consiste en modo alguno (opinión de Blancherau), de modo necesario y como regla ordinaria, en una cierta atracción interior del sujeto ni en una invitación del Espíritu santo a abrazar el sacerdocio"45.

Esta conciencia y esta praxis se ha mantenido sin cambio alguno en el llamamiento para el episcopado -no serían bien vistos ni se aprobarían "aspirantes" o "candidatos" que procurasen o se ofreciesen espontáneamente para este ministerio-. Y es la praxis que se ha comenzado a seguir en la elección de los diáconos permanentes en todas las iglesias. Solamente en lo que se refiere al ministerio presbiteral se sigue de ordinario la praxis de esperar a los que se ofrecen como voluntarios desde el sentimiento o la convicción de tipo subjetivo de haber sido objeto de un llamamiento directo, inmediato, de Dios.

44 En todos los estudios se citan casos paradigmáticos de elegidos para la ordenación sin ellos quererlo, como los de Gregorio de Nacianzo, Gregorio de Nisa, Juan Crisóstomo, Martín de Tours, Paulino de Nola, Agustín de Hipona, Ambrosio de Milán. Gregorio de Nisa y Juan Crisóstomo escribieron una apología sobre la "huida ante la ordenación". Y se hizo proverbial la expresión de la Regla de San Pacomio de que "los monjes deben huir de las mujeres y de los obispos", por el peligro de que estos los forzaran a la ordenación episcopal, Cfr. Legrand, H., a.c. Notas 31 y 33.

45 La sentencia aprobando la tesis de Lahitton fue publicada en Acta Apostolicae Sedis 4(1912)485. Sobre esta polémica, puede verse el estudio de R. Darricau, Un débat sur la vocation au début du siècle: l'affaire Lahitton (1909-1912), en La vocation sacerdotale et religieuse en France aux XVII-XIX siècles, Angers, Université d'Angers, 1979. En dicho estudio señala con pesar cómo entre los educadores de los sacerdotes la tesis de Lahitton ha sido practicamente abandonada y se ha seguido la tesis condenada de Blancherau. Cfr. A. Legrand, a.c. nota 37. Expone en síntesis la polémica también Braud, P., Proposer l'appel. Quand l'Église appelle..., Jeunes et Vocations n. 105(2002)31-44, especialmente pp.39-42. En España se hizo amplio eco de esta polémica G. Mártil Barbero en su conocida obra Los Seminarios hoy, con la que se inició nuestra Revista SEMINARIOS, n.2, 1955. La obra fue editada también como libro por Ediciones Sígueme, Salamanca. Tampoco parece que haya sido muy seguida entre nosotros, en la práctica pastoral y educativa, la opinión de Lahitton. 
La doctrina oficial a este respecto continúa siendo la misma y ha sido nuevamente afirmada en la Pastores dabo vobis, en estos términos: "Ésta (la vocación sacerdotal) es una llamada, a través del sacramento del orden recibido en la iglesia, a ponerse al servicio del pueblo de Dios... Todo presbítero recibe del Señor la vocación a través de la iglesia como un don gratuito, una gratia gratis data (charisma)... Este elemento eclesiástico pertenece a la vocación al ministerio presbiteral como tal" (PDV 35). "En el contexto actual no falta tampoco la tendencia a concebir la relación del hombre con Dios de un modo individualista e intimista como si la llamada de Dios llegase a cada persona por vía directa sin mediación comunitaria alguna... Encontramos así otra amenaza... que hace imposible reconocer y aceptar con gozo la dimensión eclesial inscrita originariamente en toda vocación cristiana, y en particular en la vocación presbiteral" (PDV 37).

\section{Llamamiento eclesial y elección de Dios}

El "llamar por el propio nombre", constituye, pues, la experiencia fundante y las experiencias fundamentales de la existencia cristiana, y muy particularmente, la de la vocación para el ministerio ordenado en cualquiera de sus tres grados. Una experiencia de un llamamiento humano, de una voz concreta, audible, que resuena en los oídos, por parte de la iglesia, de la comunidad o de personas particulares de ella.

En un segundo momento, y desde la fe en el Dios y Padre de Jesús que dirige la historia del pueblo y la de todas las personas y que reconoce la función de ese pueblo de testigo, ámbito, signo y portavoz del proyecto divino de salvación para la humanidad, se interpretará esa con-vocatoria, esa voz, ese llamamiento, como la voz de Dios, el autor y el sujeto del proyecto, y, con toda legitimidad se atribuirá al propio Dios el acto del llamar. Más aún, desde la mentalidad bíblica, especialmente del AT, que atribuye directamente a Dios todo el acontecer humano e histórico, se llegará a presentar esa acción divina como la única existente, omitiendo casi por completo la acción humana. El último momento de este proceso será identificar el llamamiento con una voz interior, una especie de "inspiración" o "revelación", con una convicción íntima y personal, "como si la llamada de Dios llegase a cada persona por vía directa, sin mediación comunitaria alguna" (PDV 37). 
Ambos aspectos han sido bien puestos de relieve recientemente por Juan Pablo II en la Exhortación postsinodal Pastores dabo vobis "Toda vocación cristiana viene de Dios, es don de Dios. Sin embargo nunca se concede fuera o independientemente de la Iglesia, sino que siempre tiene lugar en la Iglesia y mediante ella... Ahora se puede comprender mejor la esencial dimensión eclesial de la vocación cristiana: ésta no sólo deriva "de" la Iglesia y de su mediación, no solo se reconoce y cumple "en" la Iglesia, sino que -en el servicio fundamental de Dios- se configura necesariamente como servicio "a" la Iglesia"... Esto que decimos de toda vocación cristiana se realiza de un modo específico en la vocación sacerdotal" (PDV 35).

En el llamamiento que suena en los oídos humanos y cuyo sujeto son personas o la comunidad cristiana, hecho en el nombre del Señor y de Jesucristo, con la fuerza del Espíritu, se hace presente y audible el llamamiento de Dios, el sujeto Trascendente, que actúa en la acción humana, y cuya presencia, actuación y "precedencia" se expresará con esas fórmulas presentes en buen número de las narraciones vocacionales, y que, con toda legitimidad, se han proyectado sobre toda y cualquier vocación: "antes de formarte en el seno materno..."; "me eligió desde el seno de mi madre y me llamó..." (cfr. Jr 1,4-5; Gal 1,15).

Hoy tenemos una comprensión más adecuada de esta doctrina, desde la comprensión de la iglesia como "sacramento", como manifestación y visibilización de la acción y de la presencia de Dios en la historia. Cuando la Iglesia actúa "en el nombre del Señor", esa acción no es solo el reconocimiento de la acción de Dios, es "el paso", la "mediación" de la misma. En ella y por ella Dios se hace presente en la historia. Él realiza, garantiza y da consistencia al llamamiento de la Iglesia. También aquí podemos afirmar que lo "atado-desatado" en la tierra queda "atado-desatado" en el cielo (cfr. Mt 18,18).

\section{UN PUEBLO DE LLAMADOS QUE LLAMA: de la "pastoral vocacional" a la praxis del llamamiento.}

La reflexión sobre la crisis de las vocaciones ha propiciado, además de una profundización en el hecho del llamamiento, la abertura de nuevos horizontes en la "pastoral vocacional", en la acción de la comu- 
nidad cristiana para suscitar, promover, cultivar las diferentes vocaciones eclesiales. Uno de esos horizontes nuevos, calificado ya, con una expresión de Juan Pablo II, como de "salto de cualidad" (cfr. NVNE, 13), es el paso de la "espera" de los voluntarios que se puedan ofrecer a la "propuesta", de la preocupación y de los esfuerzos por suscitar, animar o promover a la pro-vocación, es decir, al llamamiento por el propio nombre.

Este paso fue formulado en esos mismos términos de "pasar de la espera a la propuesta" ya en 1974 por el Card. Javierre, Prefecto de la Congregación de Seminarios; fue acogido por el Card. Etchegaray, Arzobispo de París, en 1978, en su homilía del jueves santo, sobre el "sacerdote, el llamado que llama"46. Fue proclamado por Juan Pablo II en el Mensaje para la Jornada mundial de oración por las vocaciones de 1979, el primero de su pontificado, en estos términos tan explícitos y significativos:

"Cristo, que mandó rezar por los trabajadores de la mies, también los llamó. Él, personalmente... Estas palabras de llamamiento están confiadas a nuestro ministerio apostólico, y nosotros debemos empeñarnos en hacer que sean oídas "hasta los confines del mundo" (Hch 1,8) como todas las otras palabras del evangelio. Es voluntad de Cristo que las hagamos oír. El Pueblo de Dios tiene el derecho de oírlas de nuestros labios. Dios es siempre libre de llamar a quien quiera y cuando quiera... Pero de ordinario Él llama: a) por medio de nuestras personas y b) por medio de nuestras palabras. Por consiguiente, no tengáis miedo de llamar. Bajad para en medio de vuestros jóvenes. Id personalmente a su encuentro y llamad. Los corazones de muchos jóvenes, y también de menos jóvenes, estás predispuestos para escucharos... Nosotros debemos llamar, el resto lo hará el Señor..."47.

En esta línea se movió ya el II Congreso Internacional de vocaciones de 1981: "La Iglesia, llamada por Dios, constituída en el mundo como comunidad de llamados, es, a su vez, instrumento del llamamiento de Dios" (n.18). De él se ha hecho eco explícito y apremiante

${ }^{46}$ La homilía, pronunciada en la Misa crismal el Jueves Santo, en la catedral de Marsella, fue publicada en francés en La Documentation Catholique, n.1740(1978)357-358. La traducción española se encuentra en Seminarios, 24(1978)229-233.

47 Texto íntegro en Seminarios, 25(1979)199-202. 
el Congreso Europeo de vocaciones de 1997: "La crisis vocacional de los llamados es hoy también crisis de los que llaman, muchas veces escondidos y poco valientes. Si no hay nadie que llame ¿cómo puede haber quien responda?" (NVNE 19). "No se puede llamar "madre" a una comunidad de creyentes que simplemente "espera", entregando totalmente a la acción divina la responsabilidad del llamamiento, como temerosa de hacer ella misma llamamientos..." (NVNE, 19).

Parece, pues, que el "llamar por el propio nombre" debiera ser el procedimiento a emprender por todas las iglesias, camino plenamente coherente con la verdad antropológica del llamar y con la naturaleza propia de la Iglesia en cuanto con-vocada, "pueblo de llamados". "La comunidad que toma conciencia de ser llamada, toma conciencia al mismo tiempo de que debe llamar continuamente" (II Congreso, 18). "La Iglesia, que por su propia naturaleza es "vocación", es generadora y educadora de vocaciones. Lo es en su ser de "sacramento" en cuanto "signo" e "instrumento" en el que resuena y se cumple la vocación de todo cristiano; y lo es en su actuar..." (PDV 35). "La vocación define a la Iglesia... Pero esta naturaleza se expresa en los llamamientos. La Iglesia llama porque es llamada. El llamamiento que recibe la atraviesa y la dirige a todos. La Iglesia es una inmensa voz, una sinfonía de nombres"48.

48 Mons. ROUET, A., Une Église appelée et appelante, Jeunes et Vocations n.91(1998) p. 36. Esta perspectiva se encuentra tratada con mucha frecuencia ya en el ámbito de lengua francesa, especialmente en la Revista ya citada "Jeunes et Vocations", del Servicio Nacional de Vocaciones de Paris. En dicha revista los nn. 89.90 .91 y 92 (1998-1999) están dedicados específicamente al tema Former une Église qui appelle. Recomendamos los siguientes estudios: C. ROUBINET, L'appel, n.90(1998)5-13; D. VILLEPELET, Appeler à plus!, n.89(1998)5-9; J. M. LAUNAY, Susciter toutes les vocations chrétiennes, dons de Dieu, appels de l'Église, n.92(1999)11-26; Mons G. PONTIER, Une Église appelée et appelante, n.90(1998)61-66; Mons A. ROUET, con el mismo título, n.91(1998)31-36; M. BEGUIN, Si l'Église vous appelle... La communauté paroissial, lieu privilegiée de l'appel du Seigneur, n.90(1998)47-50. Otros títulos de interés en la misma revista son: J, OURIS, Par nous Dieu appelle, n.58(1990)85-93 (crónica del Congreso de Vocaciones celebrado en Angers en octubre de 1989 bajo ese título); P. BRAUD, Quand l'Église appelle, n.105(2002)31-44; R. COFFY, Sommes-nous tous appelants?, n.37(1985); J.-P. RUSSEIL, Initier une culture de l'appel, n.93(1999)53-61. Mons. F. DENIAU, Appeler des prêtres, n.109(2003)89-104. Además son de enorme interés: el n. monográfico de la Revista Prêtres Diocesains, sobre L'appel au ministêre presbyteral n.1213(1983); Mons. E. Marcus, Des laïcs serviteurs de l'appel, ECHO 104(1991); Id. Des jeunes en marche: du service à l'appel, ECHO 100(1990); M. COLONI, Vocations, oeuvre de l'Église, Prêtres Diocesains, n.1257(1987)519-522. 
No estará de más, por tanto, que como síntesis y consecuencia de todo lo dicho, ofrezcamos algunas pistas de actuación que puedan ayudar a dar este paso de "la espera a la propuesta" 49 , del "promover o suscitar" al llamar por el propio nombre, de la pastoral vocacional a la praxis del llamamiento.

1. La primera acción será el "redescubrir el llamamiento fundador"50, es decir, hacer consciente a cada cristiano de su propia historia de salvación que comienza con el llamamiento personal en el bautismo; de que dicho llamamiento lo constituye en miembro activo y responsable, con las capacidades y aptitudes que el Espíritu ha depositado en él, de esa misma iglesia que le ha llamado; hacerlo sensible también a la serie de sucesivos llamamientos que le podrán ser dirigidos para que colabore, en el ejercicio de su condición regia, sacerdotal y profética, en la construcción de la misma comunidad eclesial, y, a la vez, a la responsabilidad de prestar voz al Señor para llamar a otros para la construcción del reino de Dios en el mundo.

2. Un segundo capítulo de actuación tendrá como objetivo el crear y cultivar en cada comunidad la relación pastoral primaria, en la línea de la del Buen Pastor que conoce y llama a cada uno por su nombre (cfr. Jn 10). Un tipo de relación interpersonal caracterizada por el "conocimiento mutuo" y el "llamarse por el propio nombre". Las comunidades deben ser convocadas constantemente a pasar de "sociedades anónimas" a "sinfonías de nombres", a asambleas de personas que se encuentran y se reconocen en su propia personalidad, que mantienen relaciones de cercanía y de afecto, que se conocen entre sí. Y porque se conocen y conocen sus capacidades y carismas, se llaman por sus propios nombres y mutuamente se invitan a poner esos carismas al servicio de la comunidad y del evangelio.

49 Es el título que dimos al Editorial publicado en Seminarios el año 1986 (vol.32, pp.5-11) inspirado en el título y en el contenido en la intervención ya aludida de Mons. A. M. Javierre.

${ }^{50}$ La expresión es de Mons. A. Rouet, en Une Église appelée et appelante, Jeunes et Vocations n.91(1998)33. 
3. Instaurar y desarrollar la cultura del llamamiento: de llamamiento en llamamiento... Toda la vida parroquial es ya hoy un poco por todas partes, y debe llegar a serlo cada vez más, una invitación o llamamiento constante para los diversos servicios que el anuncio de la palabra, el servicio de la caridad, la animación de la liturgia, las realizaciones de la comunión interpersonal, exigen. Estos llamamientos deben ser profundizados desde esa conciencia de que en ellos se hace visible el llamamiento de Dios, y, por consiguiente, la responsabilidad personal ante ellos y su ejercicio.

Estos llamamientos deben pasar de genéricos a personales, por el propio nombre; de una simple "invitación", que no deja de ser una demanda de "voluntariado", a la designación, a la encomienda personal de uno u otro de los servicios o ministerios necesarios a partir de la personal vivencia de fe, del conocimiento de las capacidades propias de cada persona y de las demandas de las necesidades eclesiales 0 sociales de cada ambiente y momento. "Un poco por todas partes hay personas que tienen capacidades para cumplir estas misiones, no como una carga impuesta desde el exterior, sino como la expresión de aquello que tienen de más íntimo. El llamamiento a estos encargos constituye un reconocimiento confiante de lo que ellas ya son... Entonces los cristianos se llaman unos a otros para formar equipos. Cada uno es responsable de llamar a otros... esto es la "cultura del llamamiento". Esta cultura hace a cada cristiano responsable por su parte de la circulación del llamamiento. Llamar se convierte en un bien común de una Iglesia" 51 .

Y, como el llamamiento, como vimos, descubre horizontes existenciales, posibilidades nuevas de realización de sí mismo, hay que hacerlo circular no solo de persona a persona sino también de "llamamiento en llamamiento" en una misma persona, para que pase de un servicio a otro, avanzando hacia llamamientos cada vez más comprometedores, hacia responsabilidades más amplias y profundas. Para estos llamamientos hay que extender la mirada a todos. No conviene pensar sólo en los que se ofrecen espontáneamente, ni sólo en personas especiales con capacidades extraordinarias, ni en los que muestran una

51 Mons. A. Rouet, a.c. 35. 
inclinación marcada o tienen una sensibilidad especial, ni tampoco exclusivamente en los que mantienen una práctica religiosa habitual. "Si antes la pastoral vocacional circunscribía su campo de actuación a algunas categorías de personas... ahora cada vez más se percibe la necesidad de... extender con valentía a todos el anuncio y la propuesta vocacional, en nombre de aquel que no tiene preferencias personales, que escoge pecadores en un pueblo de pecadores, que hace de Amós, que no era hijo de profetas,... un profeta, que llama a Leví y va a casa de Zaqueo" (NVNE, 13), y, tendríamos que añadir, que llama a Saulo, y de perseguidor lo convierte en el apóstol fundamental del cristianismo.

4. El llamamiento explícito para el ministerio presbiteral, y aun para la consagración religiosa.

La persona que es llamada constantemente, que camina de compromiso en compromiso, acompañada y guiada constantemente por una profundización en la fe, llega un momento en que está preparada, $y$, en muchas ocasiones, dispuesta, a escuchar y acoger invitaciones "de mayor estima y afecto".

Esta praxis era sugerida ya por el II Congreso Internacional de Vocaciones: "Trabajando en la comunidad los jóvenes descubren la realidad en que viven y los ministerios y servicios que la comunidad necesita. Y los compromisos de hoy, de acuerdo con los designios del Señor, pueden ser el preludio de una consagración definitiva para toda la vida" (n. 43). Y Juan Pablo II, como vimos en el Mensaje para la Jornada mundial de oración de 1979, es aún más incisivo y explícito: "Bajad para en medio de vuestros jóvenes. Id personalmente a su encuentro y llamad. Los corazones de muchos jóvenes, y los de menos jóvenes también, están dispuestos para escucharos..."

Para estos casos "de especial consagración", especialmente para el ministerio presbiteral, se trataría, como ya vimos que acontece para el ministerio episcopal y el diaconado permanente, de buscar cristianos que vivan apostólicamente, que se hayan mostrado eficientes, comprometidos, que posean los carismas indispensables, entre los cuales se cuenta hoy en el presbiterado el del celibato, e invitarlos, mostrándoles la necesidad salvífica a la que responde, en nombre y en el lugar de Cristo, dicho ministerio, y por lo mismo, el servicio salvífico que ofrece al pueblo de Dios. "Cuando para un cristiano las necesidades se con- 
vierten en llamadas es señal de que ha inscrito su existencia en la dinámica de la alianza y que la voz de Dios se ha hecho en ellas humana"52.

Este llamamiento por el propio nombre para el ministerio presbiteral "forma parte de la propia existencia sacerdotal... Con ello siguen un vestigio que se encuentra ya en el NT, donde se indica que el ministro debe preocuparse de tener un sucesor en su ministerio (cfr. 2 Tim 2,2)... Dios llama normalmente a través de los hombres... ;La vida prende su llama en la vida!... Y forma parte de esa vida el preocuparse también de los que puedan ser los sucesores... Hay que tener en cuenta que no es raro que los jóvenes tengan hoy día un "yo" más débil que antes... Precisamente por eso necesitan que se les anime y apoye desde fuera: necesitan a alguien que les diga: "Tengo plena confianza en ti. Tú podrías perfectamente ser sacerdote" 53 .

Pero este llamamiento puede ser también obra de la propia comunidad, de los laicos. Cada día hay más laicos que, habiendo descubierto el lugar eclesial y el sentido del ministerio presbiteral, y la necesidad del mismo para su propia existencia cristiana y eclesial, comienzan a "llamar", a "participar en el llamamiento para los ministerios ordenados" 54 .

5. Llamar en y desde la oración por las vocaciones. "Toda vocación nace de la in-vocación" (NVNE). Y toda in-vocación debe entrañar e incorporar la pro-vocación, el llamamiento explícito. Así lo entendió la primitiva comunidad cristiana en la que "cualquier decisión vocacional era precedida por la oración; cualquier elección, sobre todo para la misión, se realizaba en un contexto litúrgico" (cfr. Hch 6,1-7; 13,1-5) (NVNE 27). Y así lo entendió y lo practicó porque es la lógica de oración "que la comunidad había aprendido con Jesús cuando, ante las muchedumbres cansadas y abatidas como ovejas sin pastor, dice: la mies es mucha pero los trabajadores son pocos. Rogad, pues, al Dueño de la mies que mande trabajadores para su mies" (NVNE Ibíd.), completando esa indicación con el llamamiento explí-

52 Mons. G. Pontier, Une Église appelée et appellante, Jeunes et Vocations, n. 90(1998) p.62.

53 G. Greshake, Ser sacerdote hoy, Sígueme Salamanca 2003, 462.464.

54 Mons. A., Rouet, a.c. 36. 
cito de Los Doce y su nombramiento como apóstoles (cfr. Mt 9,36 a $10,4)^{55}$.

Este es el paradigma de toda oración vocacional. Con ella no se trata de dejar el problema de las vocaciones en manos de Dios. Se trata de que la misma oración, al "hacer memoria" mediante la lectura de la Palabra de Dios, de sus gestas salvíficas, sea una comunión de mente, alma y corazón con ese Dios de la historia, que oye los gritos del pueblo que "claman al cielo", se compadece de él y actúa en su favor llamando y enviando personas que en su nombre aporten salvación (cfr. Ex 3,7-14); se trata de dejarse conmover, de compadecerse, ante esas multitudes que gritan; de tomar conciencia de la propia responsabilidad ante esas situaciones, de que es voluntad de Dios que nadie "pase de largo" ante ellas; se trata, finalmente, de que en la oración y como fruto de ella, la comunidad, de acuerdo con los carismas de cada uno de los orantes, los elija, los llame por su nombre propio y los envíe, en el nombre del Señor, a "trabajar en la mies".

Toda oración por las vocaciones que quiera ser auténticamente cristiana ha de contemplar, como su acto final y el éxito de la misma, el llamamiento y el envío de los orantes a realizar éste o aquel servicio salvífico, y, por lo mismo, de envío en envío, de llamamiento en llamamiento, a asumir una u otra de las diferentes "modalidades" de la vocación cristiana.

La oración es, pues, el ámbito privilegiado en el que la comunidad cristiana vive su propio llamamiento y lo hace efectivo permanentemente. Así, en la oración y por la oración, la comunidad cristiana se hace sacramento del llamamiento de Dios, segura y convencida, por otra parte, de que él es también la única garantía del éxito de toda vocación.

Con la praxis del llamamiento la Iglesia se convertirá, significativamente, sacramentalmente, en "madre de vocaciones", como lo afirmara ya el II Congreso Internacional de Vocaciones (1981) en estos tér-

55 Véase en esta perspectiva los excelentes estudios de H. Rondet, M., Dieu a-t-il un projet pour chacun?, Christus 36(1989)392-399; M. Cornillon, De l'appel du Christ à l'appel de l'Église. Trois récits du NT, Bulletin de Saint Sulpice 10(1984)107-152. 
minos: "La Iglesia, llamada por Dios, constituida en el mundo como comunidad de llamados, es, a su vez, instrumento del llamamiento de Dios... Todos en la Iglesia recibieron una vocación... Todos, por eso,... deberán tener conciencia clara de ser una comunidad de llamados... Al tomar conciencia de que es llamada la comunidad toma a la vez conciencia de que debe continuamente llamar. Así continúa manifestándose el misterio del Padre que llama, del Hijo que envía, del Espíritu Santo, que consagra... La vida engendra vida" (Documento conclusivo, n. 13).

Perspectiva ésta acentuada y profundizada en el Congreso europeo de vocaciones (1997), que en su Documento final reafirma:

"La Iglesia es madre de vocaciones porque las hace nacer, con la fuerza del Espíritu, las nutre y las sustenta... Por medio y a lo largo de ese llamamiento en sus variadas formas fluye también el llamamiento que viene de Dios... No se puede llamar "madre" a una comunidad de cristianos que simplemente "aguarda", entregando totalmente a la acción divina la responsabilidad de la vocación como temerosa de hacer llamadas; o que está convencida de que los niños, y especialmente los jóvenes, saben recibir inmediatamente el llamamiento vocacional... La crisis vocacional de los llamados es hoy también crisis de los que llaman, a veces escondidos y poco valientes. Si no hay nadie que llame, ¿cómo podrá haber quien responda?” (NVNE, n. 19 d).

Solo basta desear, con el mismo II Congreso Internacional de Vocaciones, que estas verdades de orden teológico, "se hagan continuamente realidad en el orden existencial", por parte de todos los miembros de la Ek-klesía, que La Con-vocada se convierta constantemente en La Con-vocante. 